\title{
A IMPORTÂNCIA E A UTILIDADE DA LITERATURA PARA A VIDA: TRÊS PERSPECTIVAS EM DIÁLOGO
}

\section{LA IMPORTANCIA Y UTILIDAD DE LA LITERATURA PARA LA VIDA: TRES PERSPECTIVAS EN DIÁLOGO}

Talita Jordina Rodrigues*

RESUMO: Este trabalho propõe um olhar relativo à valoração da literatura, especialmente seu caráter extrínseco, ou seja, sua importância para as pessoas e para o mundo. Assim, coloca-se importância para as pessoas e para o mundo. Assim, coloca-se em diálogo três autores que tratam dessa questão de maneiras distintas: o mexicano Jorge Volpi, o brasileiro Antonio Candido e a francesa Michèle Petit. O primeiro desses autores busca na neurociência as possíveis explicações para que continuemos partiremos. Em seguida, observaremos também o que os três autores pensam a respeito de funcões gerais e funções específicas do texto literaio, tendo a ideia principal de que a literatura humanizadora Por fim, pens a idemo principal de que a literptura é humanizadora. Por fim, pensaremos à inter-relaçăo estabelecida entre as obras, o sujeito e o mundo ao qual ele faz parte. Conseguiremos pensar, a partir dessas categorias, de que maneira a literatura opera transformações e o que faz com que ela seja importante e necessária.

PALAVRAS-CHAVE: Valoração; Literatura; Jorge Volpi; Antonio Candido; Michèle Petit.
* talitarodrigues.jlle@gmail.com

Doutoranda em Teoria e História Literária, mestra em Literatura especialista em Cinema e Linguagem Audiovisual.

RESUMEN: Este trabajo propone una mirada relativa a la valoración de la literatura, especialmente su carácter extrínseco, o sea su importancia para las personas y para el mundo. Así, se pone en diálogo tres autores que tratan de esta cuestión de maneras distintas: el mexicano Jorge Volpi, el brasileño Antonio Candido y la francesa Michèle Petit. El primero de estos autores busca en la neurociencia las posibles explicaciones para que continuemos produciendo y consumiendo literatura y es por ese enfoque que partiremos. Tras esa discusión, observaremos también lo que os tres autores piensan acerca de funciones generales y funcionexto literario, teniendo la idea principal de que la literatura es "humanizadora". Por último, pensaremos a la interrelación establecida entre las obras, el sujeto y el mundo Conseguiremos pensar, a partir de esas categorías, de qué manera la literatura opera transformaciones y lo que hace que sea importante y necesaria.

PALABRAS-CLAVE: Valoración; Literatura; Jorge Volpi; Antonio Candido; Michèle Petit. 
1 PREÂMBULO: UM BREVE PANORAMA VALORATIVO

Para alguém que acaba de sair do curso de Letras ou de algum programa de pós-graduação na área da literatura, pode parecer simples discorrer sobre movimentos literários, correntes teóricas, questões como a da autoria, da recepção, ou então sobre métodos de análise de uma obra, por exemplo. Há, entretanto, um tema aparentemente mais simples que é capaz de pôr em xeque o conhecimento acumulado sobre o tema. A pergunta que muitas vezes paralisa pesquisadores da área da Literatura é: afinal, para que ela serve? No a no de 2006, Antoine Compagnon deu sua aula inaugural como professor catedrático de Literatura Francesa Moderna e Contemporânea no Collège de France e tra tou justamente desse tema. A conferência intitulada Literatura para quê? foi publicada posteriormente e ultrapassou os muros daquela universidade, passando a ecoar noutros cantos até hoje.

Compagnon, naturalmente, não foi o primeiro a expor essa preocupação. Sua fala, porém, ga nhou destaque por ter sistematizado tão bem esse problema, chamando a atenção de uma maneira especial para todo um contexto valora tivo que precisa ser revisto, discutido e lembrado. Em seu discurso está contida, implicitamente, a ideia de que ao longo do século XX - período de maior importância para a teoria literária -, os teóricos se debruçaram exaustivamente sobre cada detalhe relativo ao texto literário sem que a maioria deles se perguntasse sobre os motivos pelos quais o faziam. Compagnon ta mbém fala, desta vez explicitamente, de sua experiência pessoal no ca mpo dos estudos literários, o que, segundo ele, aconteceu de maneira desordenada e tardia. Atesta-se, contudo, que a dificuldade em responder à pergunta Literatura para quê? abrange a todos, ou seja, não somente os que, como ele, não obtiveram o conhecimento da teoria de maneira ordenada, mas ta mbém àqueles que acessaram esse conhecimento sistematicamente.

Não se trata, portanto, de ignorar discussões que já fora $m$ travadas a respeito desse tema. O que ocorre, podemos inferir, é que os textos que tratam da utilidade da literatura não costumam ser colocados em discussão da mesma maneira que são colocados os textos que tratam de outras questões dentro do universo literário, como por exemplo a questão da autoria e a questão da recepção. O que temos, então, são textos avulsos sobre esse tema gravitando em torno de teorias consistentes e formuladas a partir de múltiplos entendimentos. Uma das exceções desse cenário de solidão e isolamento em que estão os textos sobre a importância da literatura, encontra-se exatamente em Compagnon. Além de sua aula inaugura que apresenta, discute e confronta ideias diversas sobre 
o assunto, o pesquisador já havia dado espaço ao tema da valoração em seu famoso manual de teoria literária intitulado $\mathbf{O}$ demônio da teoria, cujos capítulos foram divididos nos temas: a literatura, o autor, o mundo, o leitor, o estilo, a história e, por fim, o valor.

A proposta deste trabalho, portanto, é de dar continuidade ao que Antonie Compagnon produziu. Usá-lo não como fonte principal, mas como inspiração para colocar em diálogo outros textos que se propusera m a responder ao questiona mento a respeito da utilidade e da importância da literatura. Os textos escolhidos vêm de lugares e épocas diferentes e também fazem abordagens diferentes sobre o assunto. O primeiro deles é do brasileiro Antonio Candido, intitula-se $\mathbf{O}$ direito à literatura e foi escrito muitos anos antes da conferência de Compagnon. Os dois outros são posteriores, tanto às ideias de Candido quanto à exposição do pesquisador francês, e vêm do México e da França. São eles: Leer la mente do mexica no Jorge Volpi - ainda inédito no Brasil - e A arte de ler - ou como resistir à adversidade da francesa Michèle Petit.

Esses três textos que serão discutidos aqui têm, podemos dizer, a mesma ânsia que um jovem pesquisador da literatura ao tentar provar que ela, assim como seu próprio trabalho, não é, de ma neira alguma, dispensável. Aqui cabe ressaltar que esse interesse em justificar a presença da literatura no mundo não é algo aleatório. Podemos pensar essa a titude como um dado da história, localizando o surgimento dessa preocupação juntamente com o surgimento da modernidade. Como se sabe, o fim da soberania teocêntrica culminou com um período em que a ciência e a razão passaram a exercer grande poder sobre o pensamento humano. Logo, a objetividade iluminista ganhou prestígio em detrimento da subjetividade mística que se observava na Antiguidade e na Idade Média. Vimos, portanto, a literatura sendo acossada em diversos momentos dos últimos séculos, assim como aconteceu com outras artes, crenças e teorias mais subjetivas que foram relegadas à categoria de perfumaria. Os pesquisadores apontados aqui conhecem muito bem os argumentos do pensamento cientificista e utilizam meca nismos bastante objetivos do mundo. Volpi trabalha com estudos neurocientíficos, Petit apresenta experiências empíricas e Candido propõe uma leitura a partir do Direito, campo que não é precisamente pertencente às chamadas ciências duras, mas que tem a mplo prestígio. Passemos a acompanhar, portanto, essas armas utilizadas em defesa da literatura. 


\section{A NEUROCIÊNCIA E A LITERATURA}

Em seu ensaio chamado Leer la mente, Jorge Volpi propõe uma revisão de estudos científicos, em especial aqueles do ca mpo da neurociência, como forma de identificar situações em que o cérebro humano mobiliza a narrativa ou é mobilizado por ela. Para ele, podemos pensar em quatro situações, principalmente: a consciência, a memória, a emoção e a empatia.

A primeira delas, a consciência, é por si só relacionada à narrativa. Isso porque, se admitirmos que entre as características que nos distinguem dos outros a nima is está nossa consciência de nós mesmos, ou seja, nosso "eu", veremos que esse mesmo "eu" é, nada mais, nada menos, que uma construção narrativa. Para explicar esse pensamento, Volpi mergulha nas concepções e estudos sobre o cérebro e resga ta aqueles que ga rantem que nossa mente é a única híbrida, ou seja, "formada no sólo por las neuronas y sus moléculas asociadas, sino por las ideas o símbolos generados en ellas" (VOLPI, 2011, p. 32). Nesse sentido, a consciência pode ser entendida como algo imaterial que produz simbologias dentro de nosso cérebro, entre as quais estão: a ideia que fazemos de nós mesmos e ta mbém a ideia que fazemos dos outros, além da ideias a respeito das coisas do mundo. Tudo o que temos contato é, portanto, uma ficção criada por esse mecanismo.

Em relação à memória, Volpi ressalta que, graças a ela, além de sermos produto de uma ficção, a ficção do eu, somos ta mbém autores de ficção o tempo todo. Isso porque mobilizamos nossa memória, busca mos padrões já armazenados e, assim, produzimos novas combinações, ou seja, narrativas. Para ressaltar a complexidade dessa ação, Volpi lembra que além de nos distinguirmos dos outros a nimais, somos ta mbém diferentes dos robôs. Isso porque, enquanto a famosa Máquina de Turing - predecessora do computador e da inteligência artificial - trabalha com séries, nosso cérebro a tua em paralelo. Esse mecanismo permite que os padrões extraídos de nossa experiência sejam armazenados sepa rada mente, mas sempre com ligações a outros padrões e a outras experiências. Quando estamos diante de uma experiência nova, por exemplo, rapida mente buscamos referências de elementos dessa experiência em outras experiências do passado. Entretanto, quando acionamos experiências do passado, elas aparecem de mãos dadas com outras experiências. Assim, vamos aciona ndo nossa memória que guarda nosso conhecimento do mundo a partir de experiências e, ao mesmo tempo, va mos refazendo essa memória sob novas perspectivas. Ao rememorar constantemente de 
coisas com as quais já nos deparamos, criamos novas relações e, portanto, novas narrativas.

Além da consciência e da memória, Volpi sinaliza a emoção e a empatia como outros elementos estudados na neurociência que são capazes de provar as relações inevitáveis e necessárias que temos com a narrativa. E aqui chega mos ao principal argumento do autor em defesa da literatura. Esse argumento vem de um estudo que descobriu neurônios específicos em nosso cérebro e que foram chamados de neurônios espelho. Eles são, de um modo geral, os responsáveis ta nto pela imitação qua nto pela empatia. Quer dizer, são precisamente esses neurônios que explicam o fato de nos comovermos diante de uma pessoa que chora, por exemplo. O que acontece nesse momento é que nos colocamos no lugar dessa pessoa, fingimos ser ela e portanto tentamos sentir o que ela sente. Aqui é importante deixar claro que não fazemos isso porque somos bons, mas precisamente porque esse é um mecanismo de proteção. Fazemos isso com a intenção clara de tentar antever alguma situação e, logo, nos prepararmos para ela. Ora, se estamos diante de uma pessoa furiosa, nossos neurônios espelho nos fazem compreender o que essa pessoa está sentindo para tentar prever que ela, por exemplo, possa nos agredir fisicamente.
Isso acontece no plano de nossas experiências reais, mas curiosamente se repete da mesma maneira quando estamos diante de uma ficção. Quando lemos sobre uma personagem que está se sentindo injustiçada, por exemplo, nos colocamos no lugar dela, sentimos o que ela sente e, por fim, a compreendemos. É claro que sabemos que Ema Bovary ou Sancho Pança são personagens inventados, ou no máximo inspirados em pessoas reais, mas isso não nos impede de, em alguma medida, sentirmos empatia por eles. Sabemos que nossa inteligência é complexa o bastante para distinguir e identificar, em algum grau, qua ndo um acontecimento é real ou quando ele é inventado, mas esse é um dado que parece ser irrelevante ao nosso cérebro. Inclusive, segundo Volpi (2011), é precisamente esse exercício de ignorar a veracidade de uma narrativa que fez com que ela surgisse no mundo e perdurasse entre nós, huma nos. Nas palavras de Volpi: "La ficción se inaugura, pues, no cua ndo el primer humano miente, sino cuando los demás reconocen su mentira y prefieren ignorarla.” (VOLPI, 2011, p. 22)

3 Função geral e funções específicas

Para Sherazade que, de acordo com o imaginário persa, contava, ao longo de diversas noites, aventuras e 
histórias fantásticas ao rei Shariar a fim de evitar que ele a matasse, a literatura tinha a função primeira de garantir sua sobrevivência. Seu valor se justificava pela sua capacidade de preservar uma vida. Ao fim das Mil e uma noites, ficamos sabendo, porém, que para além dessa preservação, a literatura havia operado uma transformação em seu receptor, o rei, que agora desistira de matar sua amante. Tomamos a história clássica oriental para pensarmos no valor, ou melhor, nos valores que a literatura tem. Em primeiro lugar, cabe distinguir dois tipos possíveis de valor para o termo literatura: o que diz respeito ao caráter intrínseco, ou seja, o valor de um texto específico ou sua qualidade estética; e o que diz respeito ao caráter extrínseco, cujo valor é mais amplo, referindo-se à literatura enquanto arte, meio de comunicação e instrumento social. E dessa literatura que estamos tratando e é a partir dela que podemos pensar ta mbém outras subdivisões de valores.

Como no exemplo de Sherazade, a literatura pode ter um valor específico, que seria o de manter a personagem viva, e ta mbém um valor mais geral, no caso, o de transformar o rei em um ser humano melhor. Usamos, portanto, essa ideia para entender o que Jorge Volpi, Antonio Candido e Michèle Petit defendem a respeito da importância da literatura. Comecemos pelo seu valor ou melhor, sua função, como trata remos aqui, num âmbito mais geral. É essa função geral que dá uma visão a mpla do valor que tem a literatura. Além disso, partimos dessa função porque o pensamento de todos os autores coincidem. Tanto para Volpi, quanto para Candido e para Petit, a literatura tem uma função humanizadora. Os motivos que levam os autores a esse entendimento, entretanto, são variáveis e, portanto, podemos extrair de suas falas diversas funções específicas atribuídas à literatura. Essas funções específicas não são, obviamente, tão específicas quanto a função de preservar a vida de Sherazade, mas servem de justificativa para pensar a função geral humanizadora da literatura.

No caso de Jorge Volpi, a ideia de que a literatura é humanizadora parte do argumento desenvolvido sobre os neurônios espelho e a empatia. Ora, se temos a possibilidade de presenciar representações tão diversas dos seres humanos e se, com essas representações, colocamo-nos no lugar deles e sentimos junto com eles, logo os entendemos e ta mbém nos tornamos mais humanos.

No quiero exagerar: leer cuentos y novelas no nos hace por fuerza mejores personas, pero estoy convencido de que quien no lee cuentos y novelas -y quien no persigue las distintas variedades de la ficción - tiene menos posibilidades de

Teoria, Crítica Literária, outras Artes e Mídias 
comprender el mundo, de comprender a los demás y de comprenderse a sí mismo. Leer ficciones complejas, habitadas por personajes profundos y contradictorios, como tú y como yo, como cada uno de nosotros, impregnadas de emoción y desconcierto, imprevisibles y desafiantes, se convierte en una de las mejores formas de aprender a ser humano. (VOLPI, 2011, p. 16)

Nessa ideia de Volpi está contida, naturalmente, a ideia de que quem lê literatura tem acesso a um repertório muito mais a mplo de mundo. Assim, chegamos a um dos itens que Candido coloca em sua lista de funções específicas da literatura para cumprir esse papel humanizador que é sua função geral. Segundo ele, é impossível negar que a literatura é, entre outras coisas, uma forma de disseminar e adquirir conhecimento. Para isso, ele elenca uma série de exemplos, de situações reais em que camadas mais populares foram assumindo postos mais altos dentro da intelectualidade depois de terem acesso a obras clássicas da literatura. Isso ocorre porque, segundo Candido, a aquisição do conhecimento por meio da literatura pode ser entendida, inclusive, como "incorporação difusa e inconsciente". (CANDIDO, 2011, p. 178)

Da mesma forma que a aquisição do conhecimento por meio da literatura pode acontecer de maneira involuntária, como propõe Candido, o autor ta mbém ressalta esse caráter involuntário na própria relação do homem com a ficção. Assim como Volpi explica que, por meio da consciência e da memória, produzimos e consumimos ficção o tempo todo sem nos darmos conta, Candido ta mbém reforça: "ninguém é capaz de passar as vinte e quatro horas do dia sem alguns momentos de entrega ao universo fabulado" (2011, p. 176). Logo compreendemos que, antes de justificarmos a presença da literatura no mundo, temos que ter em mente que, mesmo se quiséssemos extingui-la para sempre, isso não seria completamente eficaz, já que a narrativa está presente em nossa vida mesmo quando não abrimos um livro, vemos um filme ou assistimos a uma peça de teatro.

Mas voltemos às funções específicas da literatura para Antonio Candido. Além de transmitir conhecimento, para Candido (2011, p. 178) a Literatura assume outras duas "faces", como ele mesmo nomeia. Essas duas faces podem ser entendidas como sendo pertencentes a dois âmbitos distintos: o individual e o coletivo. $\mathrm{Na}$ mesma esteira, a pesquisadora Michèle Petit ta mbém expõe casos reais em que a literatura contribuiu tanto com sujeitos específicos qua nto com comunidades inteiras. É precisamente disso que trataremos na sequência. 


\section{A LITERATURA, O EU E O MUNDO}

Para Candido, um dos primeiros papéis que a literatura desempenha é o de orga nização do mundo. Isso porque a produção literária consiste, objetivamente, em escolher palavras e ordená-las ou organizá-las. Essas palavras são retiradas do caos, ou seja, de um universo desordenado e quase infinito, visto que está sempre em transformação, como é o léxico de uma língua. Porém, ao retirar elementos desse caos, reordená-los a ponto de produzir sentidos, a literatura ensina o homem a orga nizar ta mbém o mundo. E isso tem a ver com a organização do próprio mundo e do mundo como um todo. Quer dizer, aos nos depararmos com a perfeita disposição de elementos escolhidos por um autor, nós nos dispomos a seguir essa orga nização em nossa cabeça, logo passamos a fazer juízos do mundo de maneira mais lógica e ordenada.

Essa organização do mundo ocorre, como já menciona mos, em duas vias: a interna, ou pessoal, individual; e a externa, que é, podemos dizer, regional ou universal. Da mesma maneira que Antonio Candido, a pesquisadora Michèle Petit trabalha, em seus capítulos 2 e 3 de A Arte de Ler, com exemplos de sujeitos que conseguiram reorganizar seus mundos externos ou seus mundos internos a partir do contato com a literatura. Para apresentar esses casos reais, Petit percorreu a América Latina e acompanhou experiências de dezenas de projetos sociais relativos ao universo literário e que trabalhavam especialmente em comunidades e grupos afetados por algum problema social. O objetivo desse trabalho, portanto, era buscar experiências que comprovassem a função humanizadora da literatura, já que elas provinham de situações-limite, ou seja, eventos em que a transformação pode ser mais visível.

Petit chama de fuga ou saída do caos aquilo que Candido chama de função organizadora do mundo exterior. Para ilustrar bem essa ideia, a pesquisadora partiu de um exemplo da Colômbia, país há muito tempo abalado pelos efeitos do narcotráfico e de facções. Lá um profissional da área das Letras começou a trabalhar com a leitura e a discussão de obras literárias em um grupo de adolescentes envolvidos, de alguma maneira, ou com a guerrilha ou com os grupos paramilitares. Esse exercício proporcionou, segundo ela, a abertura de novos mundos para esses sujeitos. Eles passaram a falar de outros universos distantes daquele mundo caótico em que eles estava $\mathrm{m}$. O resultado do envolvimento desses sujeitos com a literatura significou, portanto, um meio de transição, um portal que permitiu a fuga desses sujeitos para o outro lado do muro. 
Tanto esse como outros exemplos mencionados na obra de Petit procuram ilustrar o que ela chama de espaço transicional da literatura, ou seja, a capacidade que a narrativa tem em tornar o mundo mais habitável, mesmo quando falamos de leitores que vivem em um mundo cuja característica principal é o caos. É, naturalmente, a organização do mundo, lembrando as palavras de Candido, que faz com que esses sujeitos acessem e reflitam sobre outras possibilidades de vida. Além dessa mudança, esse espaço transicional ta mbém é capaz de despertar ações efetivas, como aconteceu em duas situações registradas na Venezuela e acompanhadas por Petit. Nesse país, também bastante precário sob diversos aspectos humanos e sociais, sujeitos que tiveram contato com a literatura em projetos específicos decidiram trabalhar na mudança de seus bairros e comunidades, como por exemplo, com mutirões de pintura e reforma de espaços coletivos.

Para além dessa organização do mundo exterior, há ainda o que Petit apresenta em relação a casos em que existe ta mbém uma fuga ou saída do caos interior. $\mathrm{Na}$ Argentina, por exemplo, um trabalho realizado com doentes terminais e seus familiares contribuiu para a cura do trauma desses sujeitos, assim como a produção de um autoconhecimento e ta mbém aceitação em relação às suas condições. Naturalmente, esse efeito interior está ligado ao caráter terapêutico que a litera tura é ta mbém capaz de operar. Esse caráter aflora sentimentos, desperta emoções e principalmente faz surgir a sensibilidade dos sujeitos em relação a sua própria existência, como o que aconteceu em um hospital de Bogotá que abriga jovens dependentes químicos e em situação de rua, outro caso apontado por Petit. A partir das leituras e discussões, segundo a pesquisadora, os jovens abriram caminho para a interioridade e passaram a reorganizar suas próprias experiências, assim como Candido já argumentava.

Em outra situação narrada por Michèle Petit, jovens de um centro de detenção, participantes de um projeto de leitura, no México, passaram a falar de temas precisamente ligados aos sentimentos, especialmente o a mor que, para surpresa do mediador, sempre aparecia no discurso dos integrantes. O resultado desse trabalho foi, inevitavelmente, o afloramento da alteridade e da compaixão. Essa ideia dialoga ta mbém com o que Volpi acredita ser uma das funções da literatura: a de despertar nossos neurônios espelho e, logo, nossa empatia. Assim, a transformação que a literatura opera do ponto de vista individual de um sujeito é primeiro a superação de um caos interior, para Petit, depois a orga nização de seu próprio mundo, para Candido, e, por fim, o despertar da compreensão do outro, para Volpi. 
Além da organização do mundo interior e do mundo exterior, Candido e Petit ta mbém concordam ao propor mais uma função específica da literatura: a de caráter social. Essa função é, naturalmente, um pouco menos individual e mais coletiva. Candido lembra que a literatura pode ser ta mbém um dos meios possíveis para a expressão, manifestação e disseminação da cultura ou do pensamento de determinados grupos. Isso quer dizer que a literatura pode ser vista como um instrumento político e social, logo um meio de transformação da sociedade de uma maneira mais ampla. Para Candido, a chamada literatura social permite que determinado sujeito conheça a situação de outros sujeitos e, por conta disso, consiga tomar posição em face disso. Como o texto de Candido trata principalmente da relação entre o campo da Literatura e o campo dos Direitos Humanos, esse é um dos exemplos mais objetivos em que as duas áreas são postas em diálogo. E aí lembramos mais uma vez a questão da empatia tratada por Volpi. Se estamos no Brasil e conhecemos, por meio da literatura, a situação degradante em que vivem habitantes de determinado lugar do continente africano, por exemplo, logo nos compadecemos com eles e, em alguns casos, nos propomos a contribuir para que essa situação se transforme.
Em relação a essa função coletiva da literatura, Michèle Petit aponta exemplos de projetos realizados no Brasil que contribuíram para construir narrativas de grupos e comunidades e, consequentemente, atuaram na memória e na transformação desses grupos. Essa experiência foi sendo disseminada e ocorreu em diversas partes, provocando uma transformação mais a mpla na sociedade. O mesmo ocorreu com clubes de leitores no México, na Colômbia e na Argentina. Muitos deles se multiplicaram e permitiram, assim, que houvesse um desenvolvimento sociocultural nesses países.

\section{CONSIDERAÇÕES FINAIS}

Pensando academica mente, poucas disciplinas são tão abertas ao diálogo quanto a Literatura. Não é por acaso que os estudos de Literatura Comparada não param de crescer e aumentar seus horizontes de discussão. Essa ideia de abarcamento poderia ser outra entre as funções específicas da literatura que contribuem para sua função maior: a de ser humanizadora. Colocar em debate assuntos tão importantes à sociedade, como a alteridade, a memória, a história, as questões de gênero, etc., é um mecanismo proposto de maneira recorrente e que, com a inclusão do texto literário, torna a reflexão mais agradável e humana. Sabemos, naturalmente, que outras artes também conseguem de certa maneira atuar nesse campo 
sociológico e com o mesmo gozo. Entretanto, sabemos ta mbém que nem sempre a literatura e as outras artes conseguem alcançar essa função maior, nem sempre elas são eficazes no desempenho dessa função.

Desde o Holocausto e pensando a partir principalmente da "Dialética do Esclarecimento", de Adorno e Horkheimer, não podemos mais nos apoiarmos esperançosamente nas artes e no conhecimento humano como instrumentos do progresso social. Ta mbém não há, sabemos, uma relação intrínseca entre estética e ética. Muitos artistas, escritores, pintores, cineastas são abertamente canalhas, infames, perversos. Da mesma maneira que até mesmo um Guernica de Picasso é capaz de suscitar não a repulsa pela violência, como parece ser a intenção do autor, mas sim o desejo de matar. Enfim, esse seria, naturalmente, um caso extremo. Em geral, a literatura e as artes desempenham funções na vida social que, como vimos, são crucialmente humanizadoras e mais do que importantes.

\section{REFERÊNCIAS}

CANDIDO, Antonio. $\mathbf{O}$ direito à literatura. In: Vários

Escritos. Rio de Janeiro: Ouro sobre azul, 2011. (p. 171-193)

COMPAGNON, Antoine. O demônio da teoria: literatura e senso comum. Tradução de Cleonice Paes Barreto Mourão. Belo Horizonte: Ed. UFMG, 1999.

Literatura para quê? Tradução de Laura Taddei Brandini. Belo Horizonte: Editora UFMG, 2009.

PETIT, Michèle. A arte de ler - Ou como resistir a adversidade. Tradução de Arthur Bueno e Camila Boldrini. São Paulo: Editora 34, 2009.

VOLPI, Jorge. Leer la mente. El cerebro y el arte de la ficción. México: Alfaguara, 2011. 